\title{
Analysis of Triple Quantum Dots Single Electron Transistor (TQD-SET)for Various Configuration
}

\author{
$1{ }^{\text {st Stephanus Hanurjaya }}$ \\ Dept. electrical Engineering \\ Faculty of Engineering Universitas \\ Sebelas Maret \\ Surakarta, Indonesia \\ 32.stephanushanurjaya@gmail.com \\ $4^{\text {th }}$ Irwan Iftadi \\ Dept. electrical Engineering \\ Faculty of Engineering Universitas \\ Sebelas Maret \\ Surakarta, Indonesia \\ irwaniftadi@gmail.com
}

\author{
$2^{\text {nd }}$ Miftahul Anwar* \\ Dept. electrical Engineering \\ Faculty of Engineering Universitas \\ Sebelas Maret \\ Surakarta, Indonesia \\ *Corresponding Author: \\ miftahwar@ft.uns.ac.id \\ $5^{\text {th }}$ Subuh Pramono \\ Dept. electrical Engineering \\ Faculty of Engineering Universitas \\ Sebelas Maret \\ Surakarta, Indonesia \\ subuhpramono@gmail.com
}

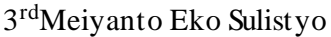 \\ Dept. electrical Engineering \\ Faculty of Engineering Universitas \\ Sebelas Maret \\ Surakarta, Indonesia \\ mekosulistyo@staff.uns.ac.id
}

\begin{abstract}
Single electron transistor (SET) has high potential for the development of quantum computing technologies in order to provide low power consumption electronics. For that purpose, many studies have been conducted to develop SET using dopants as quantum dots (QD). The working principle of SET basically is a single electron tunneling one by one through tunnel junction based on the coulomb blockade effect. This research will simulate various configurations of triple quantum dots single electron transistors (TQD-SET) using SIMON 2.0 with an experimental approach of MOSFET with dopants $Q D$. The configurations used are series, parallel, and triangle configuration. The mutual capacitance $(\mathrm{Cm})$, tunnel junctions (TJ), and temperature values of TQD-SET configurations are varied. The I-V characteristics are observed and analyzed for typical source-drain voltage (Vsd). it is found that the TQD series requires larger Vsd than parallel or triangular TQDs. On the other hands, the current in parallel TQD tends to be stable even though $\mathrm{Cm}$ is changed, and the current in the TQD triangle is strongly influenced by the $\mathrm{Cm}$. By comparing these three configurations, it is observed that the tunnelling rate is higher for parallel TQD due to higher probability current moves through three dots by applying Vds.
\end{abstract}

Keywords_-single electron transistors,MOSFETs, triple quantum dots, I-V characteristics, tunneling rates.

\section{InTRODUCTION (HEADING 1)}

Microprocessor is one of the fastest growing technologies today. A researcher who is also one of the founders of Intel, Gordon E Moore, said that the numbers of transistors in integrated circuits will double every year. This prediction is later known as Moore's law [1]. Moore's Law will eventually become obsolete [2]. This happens because the silicon and other material, which is the basic material for making transistors, will reach the point where the material cannotbe reduced again.

Single electron trans is tor (SET) is a promising solution for this problem. SET has different characteristics from other transistors [3]. SET is a transistor that works using the concept of single electron tunneling [4]. Single electron tunneling is the process of moving electrons one by one through a tunnel junction based on the coulomb blockade effect.

In this tunneling process, electrons will go through quantum dot (QD). quantum dot is an artificial atom that is used as a channel for electron transport. In this study, the QD on SET was treated like doping on a MOSFET. One application of $\mathrm{QD}$ is to make quantum-mechanical computers. Information on quantum-mechanical computers is implanted in nuclear spin from donor atoms contained in doped electronic devices [5].

Many research have studied dopants on transistors. The location of the dopant on the surface of the silicon layer can be detected using the kelvin probe force microscope (KFM)[6]. Single electron transport occurs not only in accurately placed dopants, but also in dopant-rich regions that are given dopants with conventional way [7]. Anwar M, Kawai Y, Moraru D, et al. [8] observed phosphorus dopant in silicon-based field effect transistors (FET) using the Kelvin Probe Force Microscope (KPFM). When this FET is given voltage at a low temperature $(15 \mathrm{~K})$, there is a fluctuation in the drain current [9]. This proves that there are electrons transfer occurring in the phosphorus dopant. From this observation, it can be concluded that the dopant on FET act as quantum dot because it has the same function and characteristics.

Triple quantum dots single electron transistor(TQDSET) is a SET that has three QDs in it. K. Kikoin tries to examine the tunneling process and magnetic characteristics in triple quantum dots [10]. M. Y. Fathany, et al. [11] simulates the effect of mutual capacitance $(\mathrm{Cm})$ and gate voltage (Vg) changes on the I-V characteristics of TQDSET with a parallel triangular configuration using SIMON 2.0. Another study conducted by T. Uchida, et al. [12] by making a device of series TQD. Vg value is changed to get results of the stability diagram from the device. S. Ramadhanet al. [13] simulates this experiment using SIMON2.0.

Unlike the existing research, this study will simulate TQD-SET us ing SIMON 2.0 with an experimental approach of MOSFETs with QD as dopant. Each QD is connected to tunneling capacitance. The value of the tunnel junction (TJ) and mutual capacitance $(\mathrm{Cm})$ will be changed to determine the impact on the I-V characteristics of TQD-SET.

\section{DESIGN OF TQD-SET}


Several configurations are performed using SIMON 2.0 simulators. The configurations us ed are double quantum dots configurations that are installed in series on Figure 1 and parallel in Figure 1, 2 and 3, while the parameters are shown in Table 1, 2 and 3 respectively. There are three types of capacitor junctions, namely TJ1, TJ2, CM1 and CM2 given in the circuit. TJ stands for tunnel junction and CM is middle capacitance. Quantum dots (QD1, QD2 and QD3) connected to the TJ, CM or to source or drain depends on the circuit, i.e. series, parallel or triangle type.

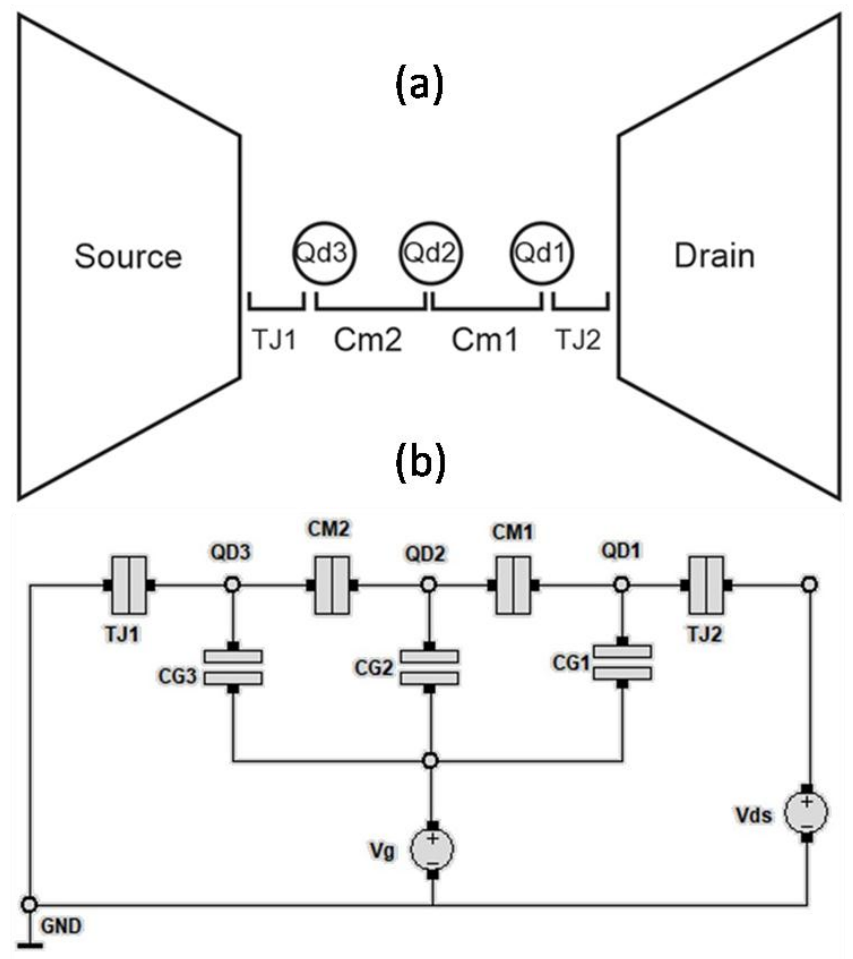

FIGURE 1. (a) Illustration and (b) circuit for simulation of series triple quant um dots single electron transistors

TABLE 1. Parameters for simulation of series triple quant um single electron transistors

\begin{tabular}{|c|c|}
\hline \multicolumn{2}{|c|}{ single electron transistors } \\
\hline $\mathrm{V}_{\mathrm{DS}}$ & $0.03 \mathrm{~V}$ \\
\hline $\mathrm{V}_{\mathrm{G}}$ & $0-0.5 \mathrm{~V}$ \\
\hline $\mathrm{C}_{\mathrm{g} 1}$ & $1 \times 10^{-18} \mathrm{~F}$ \\
\hline $\mathrm{C}_{\mathrm{g} 2}$ & $1 \times 10^{-18} \mathrm{~F}$ \\
\hline $\mathrm{C}_{\mathrm{g} 3}$ & $1 \times 10^{-18} \mathrm{~F}$ \\
\hline $\mathrm{TJ}_{1}(\mathrm{R}, \mathrm{C})$ & $2.6 \times 10^{4} \Omega, 1 \times 10^{-18} \mathrm{~F}$ \\
\hline $\mathrm{TJ}_{2}(\mathrm{R}, \mathrm{C})$ & $2.6 \times 10^{4} \Omega, 1 \times 10^{-18} \mathrm{~F}$ \\
\hline $\mathrm{C}_{\mathrm{m} 1}$ & $1 \times 10^{-18} \mathrm{~F}$ \\
\hline $\mathrm{C}_{\mathrm{m} 2}$ & $1 \times 10^{-18} \mathrm{~F}$ \\
\hline Temperature & $0 \mathrm{~K}$ \\
\hline
\end{tabular}

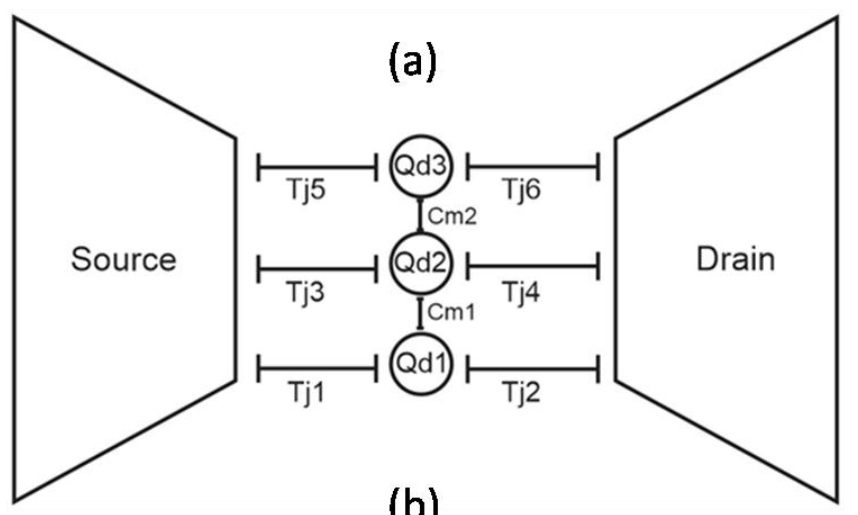

(b)

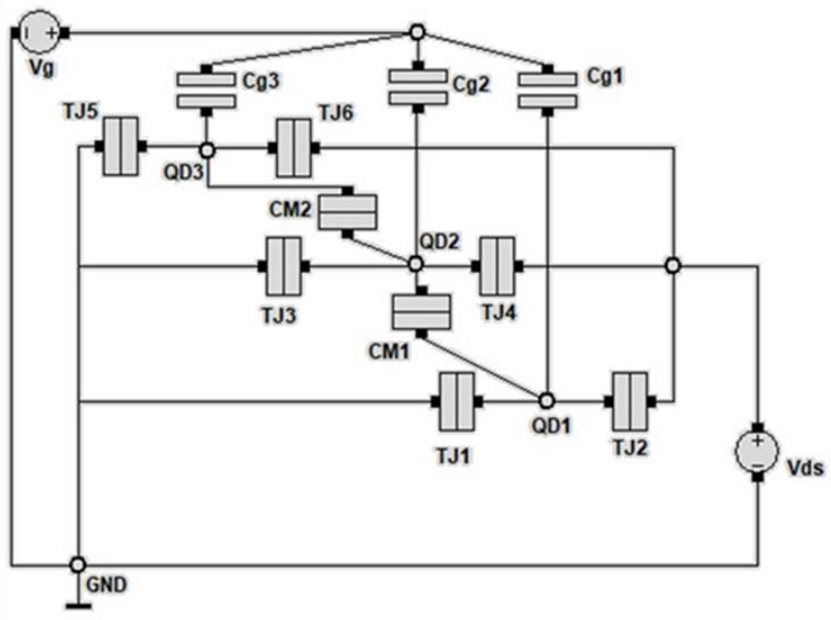

FIGURE 2.(a) Illustration and (b) circuit for simulation of parallel triple quantumdots single electron transis tors

TABLE 2. Parameters for simulation of parallel triple quantum single electron transistors

\begin{tabular}{|c|c|}
\hline $\mathrm{V}_{\mathrm{DS}}$ & $0.01 \mathrm{~V}$ \\
\hline $\mathrm{V}_{\mathrm{G}}$ & $0-0.5 \mathrm{~V}$ \\
\hline $\mathrm{C}_{\mathrm{g} 1}$ & $1 \times 10^{-18} \mathrm{~F}$ \\
\hline $\mathrm{C}_{\mathrm{g} 2}$ & $1 \times 10^{-18} \mathrm{~F}$ \\
\hline $\mathrm{C}_{\mathrm{g} 3}$ & $1 \times 10^{-18} \mathrm{~F}$ \\
\hline $\mathrm{TJ}_{1}(\mathrm{R}, \mathrm{C})$ & $2.6 \times 10^{4} \Omega, 1 \times 10^{-18} \mathrm{~F}$ \\
\hline $\mathrm{TJ}_{2}(\mathrm{R}, \mathrm{C})$ & $2.6 \times 10^{4} \Omega, 1 \times 10^{-18} \mathrm{~F}$ \\
\hline $\mathrm{TJ}_{3}(\mathrm{R}, \mathrm{C})$ & $2.6 \times 10^{4} \Omega, 1 \times 10^{-18} \mathrm{~F}$ \\
\hline $\mathrm{TJ}_{4}(\mathrm{R}, \mathrm{C})$ & $2.6 \times 10^{4} \Omega, 1 \times 10^{-18} \mathrm{~F}$ \\
\hline $\mathrm{TJ}_{5}(\mathrm{R}, \mathrm{C})$ & $2.6 \times 10^{4} \Omega, 1 \times 10^{-18} \mathrm{~F}$ \\
\hline $\mathrm{TJ}_{6}(\mathrm{R}, \mathrm{C})$ & $2.6 \times 10^{4} \Omega, 1 \times 10^{-18} \mathrm{~F}$ \\
\hline $\mathrm{C}_{\mathrm{m} 1}$ & $1 \times 10^{-18} \mathrm{~F}$ \\
\hline $\mathrm{C}_{\mathrm{m} 2}$ & $1 \times 10^{-18} \mathrm{~F}$ \\
\hline Temperature & $0 \mathrm{~K}$ \\
\hline
\end{tabular}




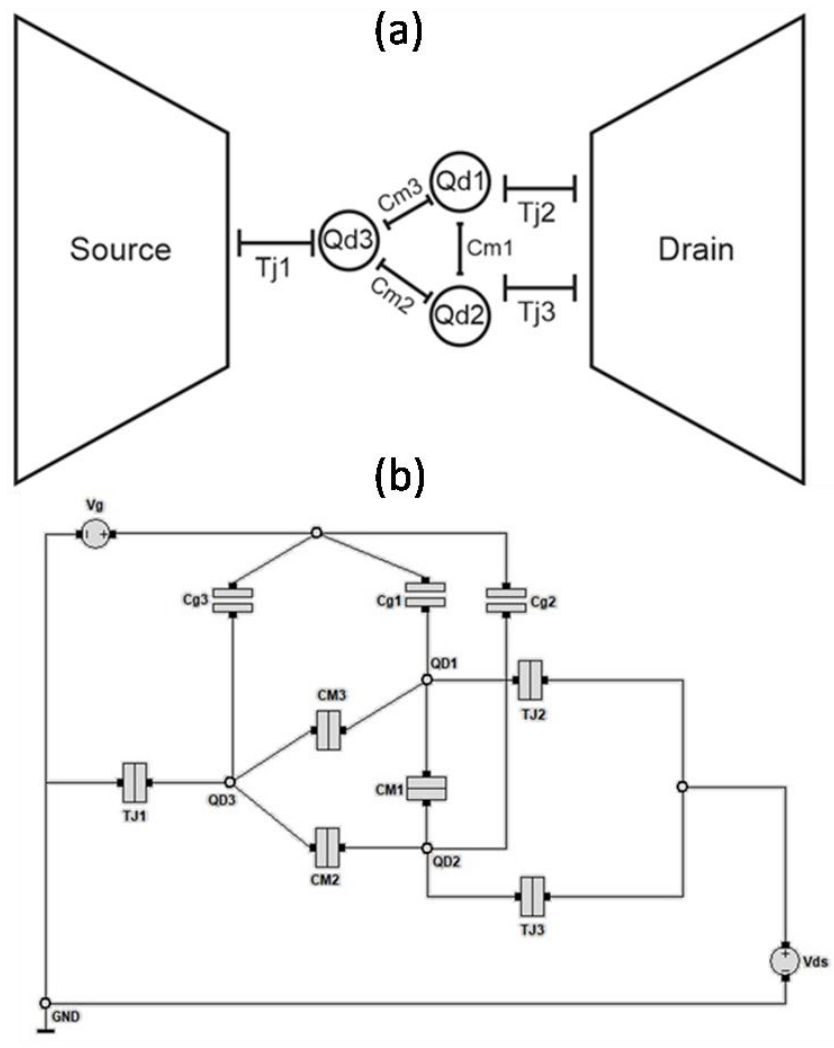

FIGURE 3.a) Illustration and (b) circuit for simulation of triangle triple quantum dots single electron transistors
TABLE 3. Parameters for simulation of triangle triple quantum single electron transistors

\begin{tabular}{|c|c|}
\hline $\mathrm{V}_{\mathrm{DS}}$ & $0.01 \mathrm{~V}$ \\
\hline $\mathrm{V}_{\mathrm{G}}$ & $0-0.5 \mathrm{~V}$ \\
\hline $\mathrm{C}_{\mathrm{g} 1}$ & $1 \times 10^{-18} \mathrm{~F}$ \\
\hline $\mathrm{C}_{\mathrm{g} 2}$ & $1 \times 10^{-18} \mathrm{~F}$ \\
\hline $\mathrm{C}_{\mathrm{g} 3}$ & $1 \times 10^{-18} \mathrm{~F}$ \\
\hline $\mathrm{TJ}_{1}(\mathrm{R}, \mathrm{C})$ & $2.6 \times 10^{4} \Omega, 1 \times 10^{-18} \mathrm{~F}$ \\
\hline $\mathrm{TJ}_{2}(\mathrm{R}, \mathrm{C})$ & $2.6 \times 10^{4} \Omega, 1 \times 10^{-18} \mathrm{~F}$ \\
\hline $\mathrm{TJ}_{3}(\mathrm{R}, \mathrm{C})$ & $2.6 \times 10^{4} \Omega, 1 \times 10^{-18} \mathrm{~F}$ \\
\hline $\mathrm{C}_{\mathrm{m} 1}$ & $1 \times 10^{-18} \mathrm{~F}$ \\
\hline $\mathrm{C}_{\mathrm{m} 2}$ & $1 \times 10^{-18} \mathrm{~F}$ \\
\hline $\mathrm{C}_{\mathrm{m} 3}$ & $1 \times 10^{-18} \mathrm{~F}$ \\
\hline Temperature & $0 \mathrm{~K}$ \\
\hline
\end{tabular}

All parameters above have been set so that the coulomb oscillation can be observed. The simulation used is stationary simulation. This simulation will simulate the occurrence of tunneling within a certain time interval. In this simulation, the time interval used is set for 10 seconds. After the simulation calculation is complete, the simulation results can be seen. The results that will be taken include: current, gate voltage.

\section{RESULT AND ANALYSIS}

The effect of changes in the $\mathrm{Cm} 2$ and $\mathrm{Cm} 1$ values of the TQD series can be seen in Figure 4. $\mathrm{Cm}$ is directly proportional to $\mathrm{Vg}$. The smaller the $\mathrm{Cm}$ value, the smaller

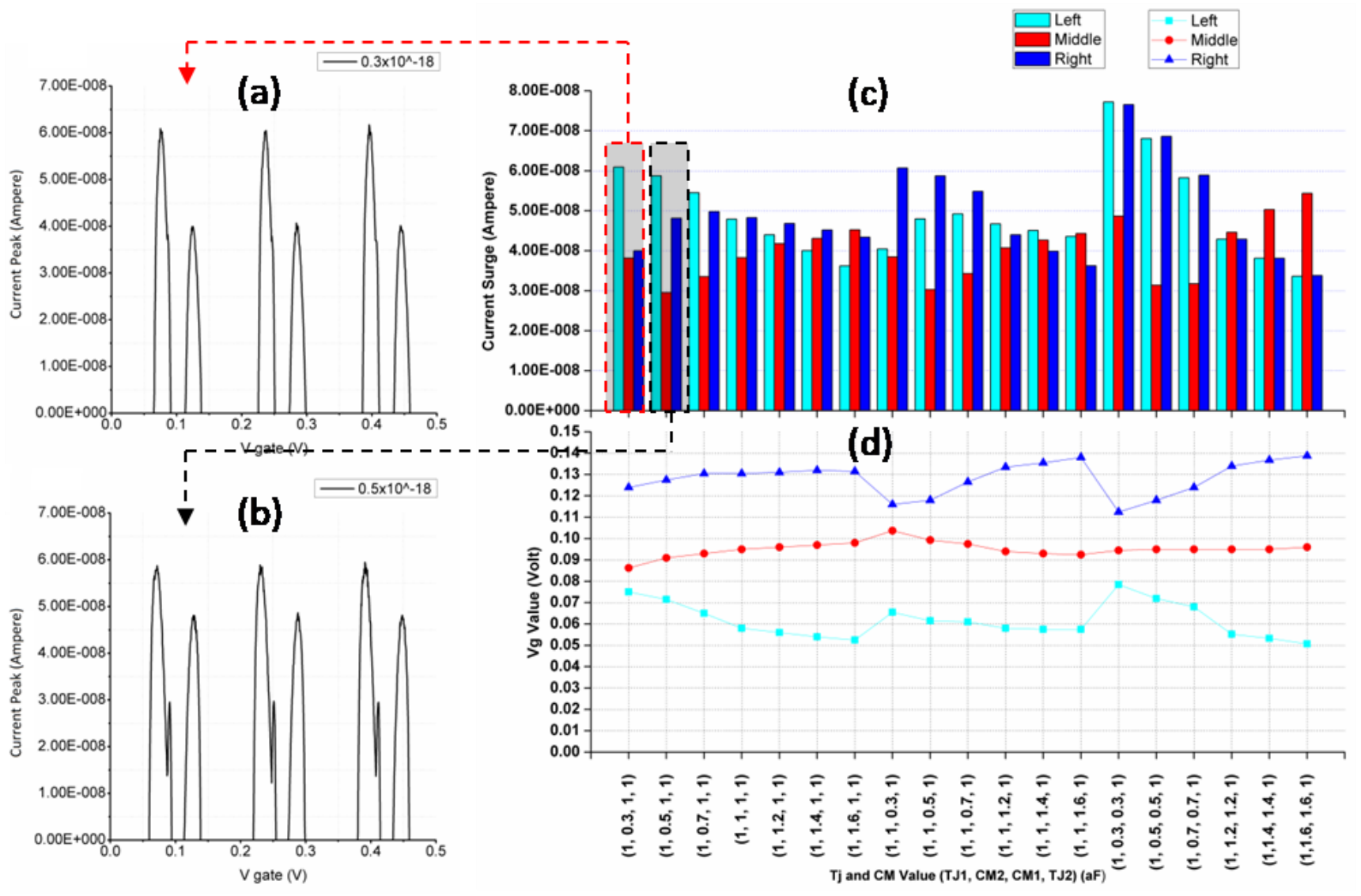

FIGURE 4.(a) and (b)An Examples of tunneling current shape correspond to (c) current peak values and (d) tunneling event in series TQD. 
$\mathrm{Vg}$ is needed for each tunneling event. The left and right current with the highest value occur when the $\mathrm{Cm} 1$ and $\mathrm{Cm} 2$ values are $0.3 \mathrm{aF}$. The highest middle current occurs when $\mathrm{Cm} 1$ and $\mathrm{Cm} 2$ are $1.6 \mathrm{aF}$.

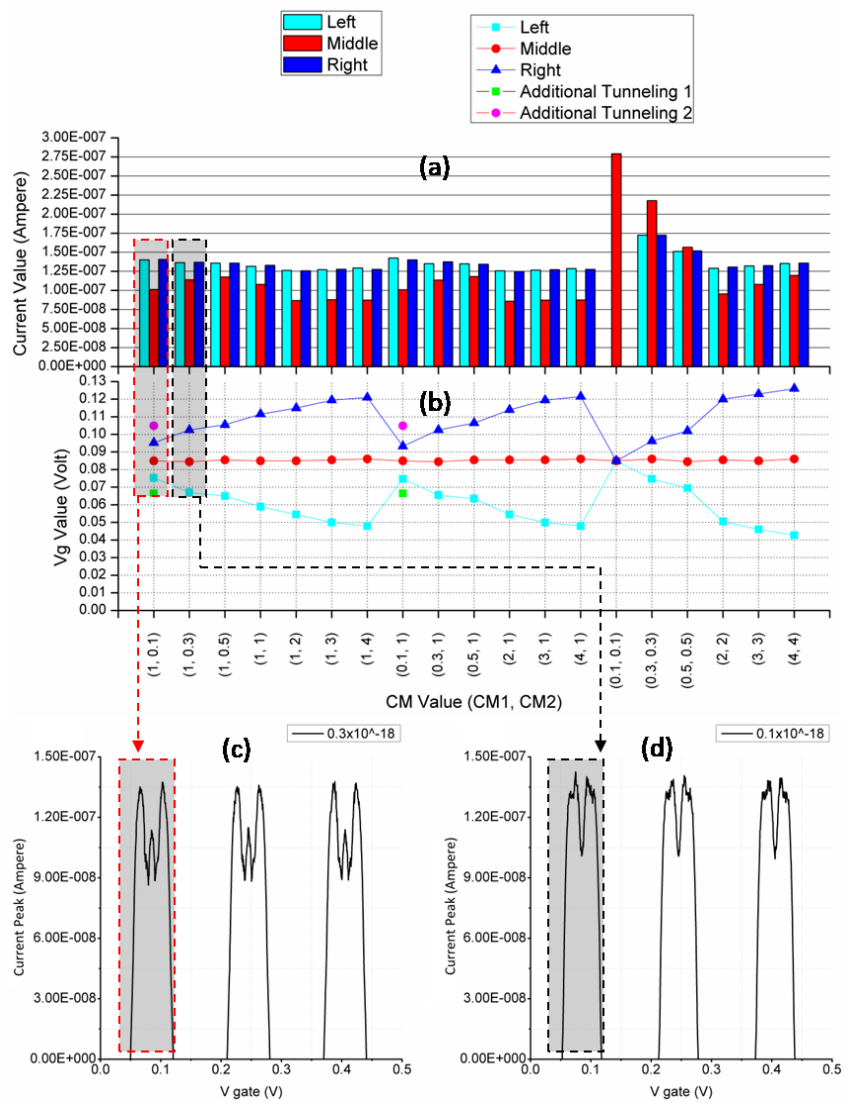

FIGURE 5. (a) Current peak values and(b) tunneling event in parallel TQD. (c) and (d) An Examples of tunneling current shape

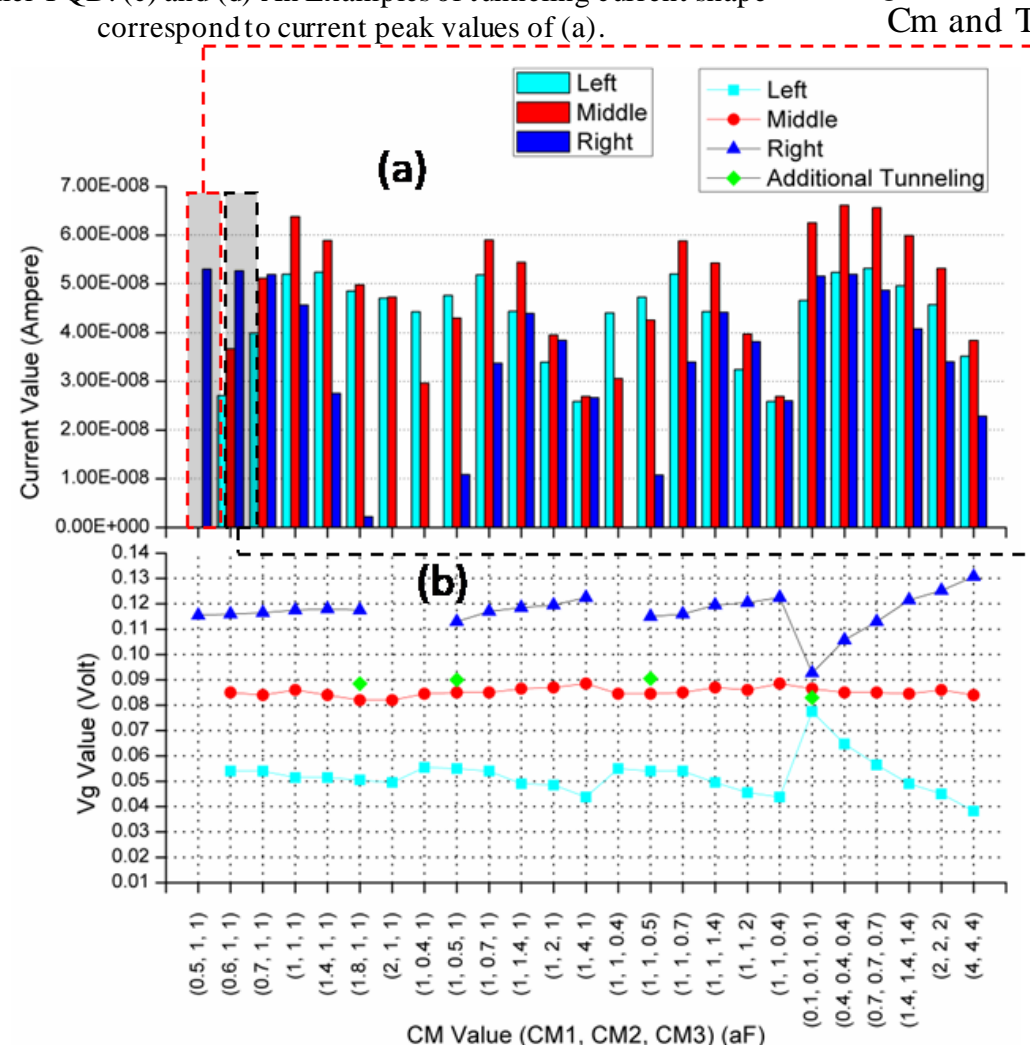

Figure 5. shows the overall data from the effect of changes in $\mathrm{Cm}$ to the current height and gate voltage ( $\mathrm{Vg}$ ). Current in parallel TQD circuits tends to be stable. Changes in the $\mathrm{Cm}$ value have the greatest effect on the middle current peak. When the $\mathrm{Cm} 1$ and $\mathrm{Cm} 2$ values are $0.3 \mathrm{aF}$, the right and left current peaks combine with the center current peak. When two or more quantum dots are brought closer, the quantum dot will form a cluster of dots. Clus ter dots will have more energy levels. This results in more electrons being able to tunnel. This can be seen from the addition of tunneling 1 and 2.

Figure 6. shows the overall data from the influence of Cm on the current height and gate voltage. In TQD SET, the smaller the $\mathrm{Cml}$ value, the lower left and middle currents peaks. At $\mathrm{Cml} 0.5 \mathrm{aF}$, the left and center current peaks are gone, leaving only the right current peak. When the entire $\mathrm{Cm}$ value is changed to $0.1 \mathrm{aF}$ the current seems to merge but when it is observed closer, it tums out that this current still has three currents peaks. When $\mathrm{Cml}$ is enlarged, the right current value gets smaller and becomes flat. At $\mathrm{Cml} 2$ $\mathrm{aF}$, the right current disappear.

\section{CONCLUSION}

The triple quantum dots single electron transistor (TQDSET) is a form of innovation from ordinary single electron transistor (SET). TQD-SET has many configuration possibilities, each configuration has different characteristics. TQD-SET series requires larger Vds than parallel TQD or triangular TQD. Parallel TQD has the highest current peak value compared to series TQD and triangle TQD. Right, centre, and left peaks in triangle TQD have different heights.

$\mathrm{Cm}$ and $\mathrm{TJ}$ affect changes of current in series, parallel,
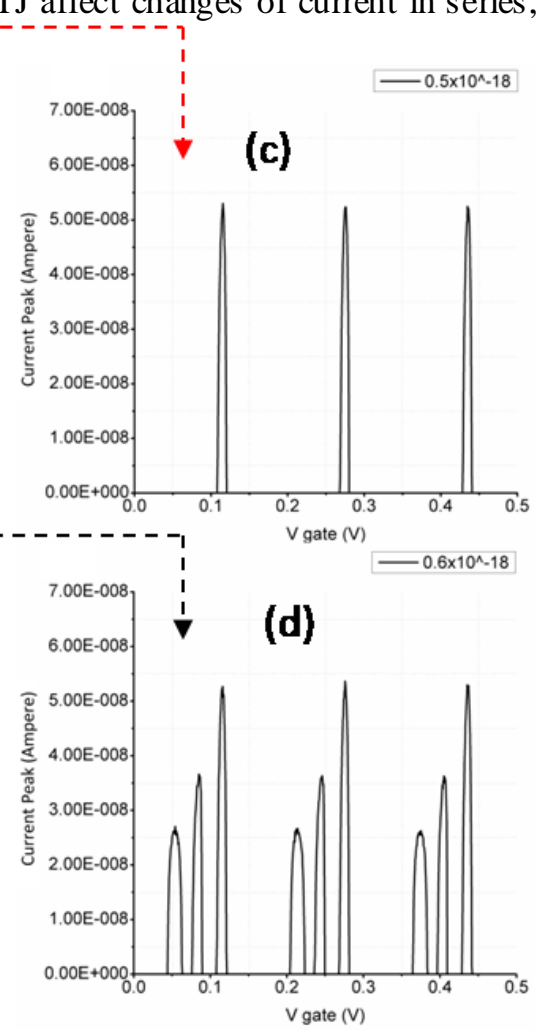

FIGURE 6. (a) Current peak values and(b) tunneling event in parallel TQD. (c) and (d) An Examples of tunneling current shape correspond to current peak values of (a). 
and triangle TQD. In the seriesTQD, Cm affects the $\mathrm{Vg}$ needed for tunneling event of electrons. The smaller the $\mathrm{Cm}$ value, the smaller the $\mathrm{Vg}$ value needed for electrons to tunnel through. The current peak value in parallel TQD tends to be stable when $\mathrm{Cm}$ is changed. Changes in the $\mathrm{Cm}$ value on the triangular TQD have the most significant impact compared to TQD series and parallel TQD. Parallel TQD has the highest tunneling rate which is caused by the high probability of movement of current through three dots when given Vds.

\section{ACKNOWLEDGMENT}

We thank R. Yusadhika Putra for his support in simulations and discussions. This work was partially supported by Grants-in-Aid for Intemational Collaboration (No: 452/UN27.21/PN/2020) and Grants-in-Aid for Fundamental Research (No: 517/UN27.21/PM/2019) from Sebelas Maret University.

\section{REFERENCES}

[1] G. E Moore, "Cramming more components onto integrated circuits," Electronics, vol. 38, no. 8, 1965.

[2] M. M. Waldrop, "Nature International Weekly Journal of Science," Macmillan Publishers Limited, 9 February 2016. [Online]. Available: https://www.nature.com/news/the-chips-are-do wn-for-moore-s-law1.19338. [Accessed 3 August 2018].

[3] A. Rasmi and U. Hashim, "Single-Electron Transistors (SET): Literature Review," Jurnal Penyelidikan dan Pendidikan Kejuruteraan, vol. 2, 2005.

[4] C. Wasshuber, "Computational Single-Electronic," in Computational Single-Electronic, New York, Springer-Verlag Wien, 2001.
[5] B. Kane, "A silicon-based nuclear spin quantum computer," Nature, vol. 393, pp. 133-137, 1998.

[6] M. Ligowski, D. Moraru, M. Anwar, T. Mizuno, R. Jablonski and M. Tabe, "Observation of individual dopants in a thin silicon layer by low temperature Kelvin probe force microscope," Appl Phys Lett, vol. 93, no. 142101, 2008 .

[7] M. Tabe, D. Moraru, M. Ligowski, M. Anwar, R. Jablonski, Y. Ono and T. Mizuno, "Single-Electron Transport through Single Dopants in a Dopant-Rich Environment," Physical Review Letters, vol. 105, no. 016803, 2010.

[8] M. Anwar, Y. Kawai, D. Moraru, R. Nowak, R. Jablonski, T. Mizuno and M. Tabe, "Single-electron charging in phosphorus donors in silicon observed by low-temperature Kelvin probe force micros cope," Japanese Journal of Applied Physics, vol. 50, no. 8S3, 2011.

[9] M. Anwar, R. Nowak, D. Moraru, A. Udhiarto, T. Mizuno, R. Jablonski and M. Tabe, "Effect of electron injection into phosphorus donors in silicon-on-insulator channel observed by kelvin probe force microscopy," Applied Physics Letters, vol. 99, no. 213101, 2011.

[10] K. K., "Tunneling and magnetic properties of triple quantum dots," Low Temperature Physics, vol. 33, no. 2, p. 105, 2007.

[11] M. Y. Fathany, S. Fuada, B. L. Lawu and M. A. Sulthoni, "Modelling and simulation of parallel triangular triple quantum dots (TTQD) by using SIMON 2.0," in AIP Conference Proceedings, 2016.

[12] T. Uchida, M. Jo, T. Fukuchi, M. Arita, A. Fujiwara and Y. Takahashi, "Evaluation of Serially Coupled Triple Quantum Dots with a Compact Device Structure by a Simultaneous VoltageSweeping Method," in Proceedings of the 16th International Conference on Nanotechnology, Sendai, Japan, 2016.

[13] S. Ramadhan, A. Alfaruq, R. Pramudita and M. A. Sulthoni, "Comparison result between simulation and experiment of coupled series triple quantum dots and its charact eristics with SIMON 2.0," in AIP Conference Proceedings, 2017. 